\title{
Objectification of the nasal patency assessment techniques used in nasal allergen provocation testing
}

\author{
Edyta Krzych-Fałta, Bolesław K. Samoliński
}

Unit of Environmental Hazard Prevention and Allergology, Faculty of Public Health and Environmental Health, Medical University of Warsaw, Warsaw, Poland

Adv Dermatol Allergol 2020; XXXVII (5): 635-640

DOI: https://doi.org/10.5114/ada.2019.81404

\begin{abstract}
Topical allergen application in nasal provocation testing (NPT) is associated with remarkably rapid changes in nasal patency. Thus, selecting the techniques of assessing the extent of nasal obstruction (as one of the responses to topical allergen application) is an important component of NPT. The study attempted to systematize and evaluate the techniques selected for assessing nasal patency during NPT based on a review of relevant literature. We reviewed the literature on the attempts to standardize the objective techniques for assessing nasal patency and their use in NPT. The best known, well-established technique for assessing nasal patency as part of NPT was rhinomanometry, followed by peak nasal inspiratory flow (PNIF) testing and acoustic rhinometry.
\end{abstract}

Key words: rhinomanometry, peak nasal inspiratory flow, acoustic rhinometry, nasal provocation testing.

\section{Introduction}

Due to their scope and their association with the relative reactivity [1] of the nasal mucosa, objective techniques for assessing nasal patency during allergenspecific nasal provocation testing (NPT) derive from two related fields: rhinology and the study of allergies. The nose, which is an exceedingly interesting and yet the least well-known organ of the human body, plays important thermoregulatory, humidifying, and purifying roles in the airways, as well as regulating airway functions. The nose plays an indirect part in gas exchange and protects the body against harmful environmental factors. Apart from its resonator and olfactory functions, the nasal cavity is an important site of specific or nonspecific reaction (response) to external factors. The contact of an allergen with the nasal mucosa of an allergic person leads to a series of events comprising the early (nasal itchiness, increased sneezing, increased production of a serous secretion, and nasal obstruction) and late [2,3] (persistent nasal obstruction and/or lower respiratory tract response) phases of an allergic reaction. This is a local anaphylactic response within the nasal mucosa to a triggering allergen. Changes in nasal patency occur rapidly, and the selection of objective assessment techniques is difficult due to a lack of standardized reference values.
This study aimed to standardize and evaluate the selection of nasal patency assessment techniques based on a review of literature on NPT. The authors of the most recent expert consensus of the European Academy of Allergy and Clinical Immunology [4] systematized the problem of selecting suitable NPT assessment tools and emphasized the important role of rhinomanometry (RMM), peak nasal inspiratory flow (PNIF) evaluation, and acoustic rhinometry (AR). These assessment techniques have been used both in outpatient/inpatient settings and in allergen challenge chambers [5].

\section{Objectification of nasal patency assessment techniques}

Objectification is defined as: "making something objective, impartial, and unbiased; making something take objective characteristics; rendering the existence of something independent of the observer" [6]. In light of the most recent standards [4, 5, 7], objectification is a particularly important and challenging problem, as not only NPT methodology itself but also selecting an alternative nasal patency assessment technique is considered controversial. The position of Polish experts on the issue of NPT methodology has been expressed in a 2010 Polish consensus [1], whereas the most recent recommenda-

Address for correspondence: Dr. habil. Edyta Krzych-Fatta, Unit of Environmental Hazard Prevention and Allergology, Faculty of Public Health and Environmental Health, Medical University of Warsaw, 1 a Banacha St, 02-097 Warsaw, Poland, phone: +48 22 599 1040, e-mail: e.krzych@gmail.com

Received: 11.12 .2018 , accepted: 24.12.2018. 
tions have been published in Alergologia Polska [8]. The techniques used for NPT include: Glatzel's mirror, RMM, rhinospirography, rhinostereometry, pressure rhinometry, rhinohygrometry, thermography, computed tomography, magnetic resonance imaging, PNIF, nasometry, AR, optical rhinometry, and exhaled nitric oxide testing. Allergen exposure chambers, especially mobile ones, have also generated much interest [5], since they are the only method of assessing the airway response to topical allergen application that mimics the natural response occurring in the patient's environment.

Certain novel assessment tools, such as optical rhinometry, are also very interesting, since they allow as sessment of both functional and structural changes in nasal patency, by showing precisely the beginning, extent, and end of an allergic response. Moreover, in comparison with other nasal patency assessment techniques, optical rhinometry has demonstrated superior specificity and sensitivity [9]. The mechanism of this assessment technique and its widespread use in rhinology and allergies were described in Otolaryngologia Polska in 2017 [10]. One of the oldest nasal patency assessment techniques was Glatzel's mirror, which evaluated the area of condensation on a metal plate following exhalation through the nose. Technological advancements have replaced this assessment tool with functional assessment techniques, such as rhinospirometry (which measures nasal air flow), rhinostereometry (which evaluates nasal obstruction via microscopic measurement of the distance between the lateral nasal wall and nasal septum), and RMM (which has constantly been one of the most commonly used diagnostic methods in rhinology) [1]. A number of studies (Grading of Recommendations, Assessment, Development, and Evaluation; GRADE) confirm the particular importance of RMM and AR, while PNIF testing is treated as a technique that could possibly replace RMM to some extent [11]. In other words, the techniques mentioned above correlate well with a subjective assessment of nasal obstruction $[11,12]$. It is important to emphasize that, apart from nasal patency assessment techniques, comprehensive NPT requires an evaluation of subjective symptoms measured both with a 100-mm continuous visual analog scale (VAS) and a discrete 0-10-point numerical rating scale (Bachert's VAS scale) $[4,7]$.

\section{Rhinomanometry}

Rhinomanometry is one of the most objective nasal patency assessment techniques. It involves measuring nasal airflow resistance based on the following parameters: the rate of nasal airflow and the pressure gradient (between the anterior and posterior nares) which generates this airflow [7-9]. The RMM can be divided into active RMM (comprising active anterior rhinomanometry and active posterior rhinomanometry) and passive RMM. Active anterior RMM involves taking measurements during a normal respiratory cycle, for each side separately, whereas active posterior RMM involves assessing the airflow in both nasal cavities simultaneously. Unlike active posterior RMM, active anterior RMM allows unilateral measurements to be made. The examined patient's nose is tightly covered with a mask connected to a pneumotachograph, with the untested nostril taped closed or occluded with a plug. Intranasal resistance is measured at the airflow of $100-150 \mathrm{ml} / \mathrm{s}$ or with a pressure gradient of $0.10-0.15 \mathrm{kPa}$ [13-17]. As in the case of active anterior RMM, active posterior RMM involves covering the patient's nose with a mask connected to a pneumotachograph measuring the pressure at the anterior nares, while the pressure at the posterior nares is measured with a sensor placed in the oral cavity (airflow $250 \mathrm{ml} / \mathrm{s}$, pressure $0.05 \mathrm{kPa}$ ). Active RMM has a number of limitations resulting from the way of measuring pressure. The difficulties associated with active anterior RMM are due to the fact that pressure measurements cannot be conducted when one of the nasal passages is completely obstructed or the nasal septum is perforated. Active anterior RMM also requires sensors (plugs) to be placed in the anterior nares, which significantly affects the physiological changes in nasal patency (nasal cycle). The technical problem associated with posterior RMM is due to the location of the posterior sensor: the patient must learn not to move the soft palate during the test because when this happens (for example during swallowing) the nasopharynx becomes separated from the oropharynx, where the pressure measuring catheter is placed. Pinching the pressure sensor's catheter against the pharyngeal wall by the soft palate produces a gag reflex, which prevents the measurement from being made in $20-50 \%$ of evaluated patients [18]. The mechanism of conducting passive RMM is reversed in comparison to that of anterior RMM. In passive RMM, it is not the patient who generates airflow by actively creating a pressure gradient between anterior and posterior nares; instead, the pressure gradient is achieved by the use of equipment. As a result, a specific volume of air is forced to pass through the nasal cavities at a constant, known rate. The assessed parameter is the pressure gradient necessary to generate such airflow and not the airflow itself. The drawbacks of this method are obtaining a single number as the test result (hence the result does not illustrate the changes in nasal airflow), the necessity for the patient to hold his or her breath, sometimes unpleasant sensations during the test, and the fact that inserting a nozzle into the nasal vestibule prevents the assessment of resistance in this nasal region $[1,18,19]$.

\section{Rhinomanometry in allergen-specific nasal provocation testing}

Experts of the International Standardization Committee on the Objective Assessment of the Nasal Airway [20] suggested a formula for calculating nasal resistance, 
$R=\mathrm{d} P / V$, where $R$ stands for resistance, $\mathrm{d} P$ stands for pressure gradient, and $V$ stands for nasal airflow rate, and using it for three pressure values: the pressure values selected for the anterior RMM were $75 \mathrm{~Pa}, 150 \mathrm{~Pa}$, and $300 \mathrm{P}$, whereas the pressure values for active posterior RMM were $50 \mathrm{~Pa}, 75 \mathrm{~Pa}$, and $100 \mathrm{~Pa}$. Physiological nasal airflow resistance is due to the structure of the nasal cavity, namely its two critical regions: the nasal isthmus and the head of the inferior concha, which is illustrated in detail by an AR graph, or rhinogram. After passing the anterior nares, inhaled air changes direction (by approximately $60^{\circ}$ ) from nearly vertical to more horizontal. At the nasal valve, the airflow rate increases by $12-18 \mathrm{~m} / \mathrm{s}$ on average, and later the airflow slows down to $2-3 \mathrm{~m} / \mathrm{s}$. This change in airflow rate is accompanied by a change in airflow character from laminar (the streams of air flowing parallel to each other and to nasal cavity walls) to turbulent flow (individual air particles moving in various directions due to the resulting pressure gradient being higher than the mean differential pressure) [1].

There have been attempts to establish reference values for nasal airflow resistance measured by RMM. These ranged from 0.20 to $0.55 \mathrm{~Pa} / \mathrm{cm}^{3} / \mathrm{s}$ for $150 \mathrm{~Pa}$ [21-23]. The final RMM result depends considerably on such factors as ethnicity [24]. The majority of studies focus on Caucasian subjects (in comparison to other ethnicities, such as African Americans). The mean reference value for healthy Caucasian adults is $0.184 \mathrm{~Pa} / \mathrm{cm}^{3} / \mathrm{s}$, whereas that for dark-skinned subjects is $0.129 \mathrm{~Pa} / \mathrm{cm}^{3} / \mathrm{s}$ and that for Asians is $0.146 \mathrm{~Pa} / \mathrm{cm}^{3} / \mathrm{s}[24,25]$. These discrepancies are most likely due to differences in nasal cavity structure.

Another important factor that must be considered in any attempts at standardization is the patients' sex. Suzina et al. demonstrated significant differences in RMM-measured nasal airflow resistance (at various levels of pressure) between the study groups of males and females. For the pressure of $75 \mathrm{~Pa}$ in males $(n=35)$ the RMM resistance, measured separately in the right and left nasal cavity, was $0.69 \pm 1.56$ and $0.41 \pm 0.20 \mathrm{~Pa} / \mathrm{cm}^{3} / \mathrm{s}$, respectively, while the bilateral resistance value was 0.19 $\pm 0.008 \mathrm{~Pa} / \mathrm{cm}^{3} / \mathrm{s}$. The same pressure value in the female group ( $n=50)$ yielded lower resistance values in the right and left nasal cavities ( $0.42 \pm 0.16$ and $0.37 \pm 0.16$ $\mathrm{Pa} / \mathrm{cm}^{3} / \mathrm{s}$, respectively), and the bilateral resistance was $0.18 \pm 0.05$. In contrast, resistance results obtained for the pressure of $150 \mathrm{~Pa}$ were significantly higher in women $(n=50)$, yielding right and left nasal cavity resistance values of $0.55 \pm 0.18$ and $0.49 \pm 0.19 \mathrm{~Pa} / \mathrm{cm}^{3} / \mathrm{s}$, respectively, with the bilateral resistance of $0.25 \pm 0.07$. In the male group ( $n=35$ ) airflow resistance in the right and left nasal cavities separately was $0.46 \pm 0.17$ and $0.53 \pm 0.23$ $\mathrm{Pa} / \mathrm{cm}^{3} / \mathrm{s}$, respectively, with bilateral resistance of 0.23 \pm 0.008 . Other measurable factors affecting reference RMM values include the patients' height and smoking status. Taller subjects as well as smokers have signifi- cantly higher nasal airflow resistance than shorter and non-smoking subjects $(p<0.06)$ [25].

The NPT measured via RMM involves assessing the airflow reduction rate at a given pressure, usually $150 \mathrm{~Pa}$. According to the most recent standards, airflow reduction of $\geq 40 \%$ at $150 \mathrm{~Pa}$ indicates a strongly positive NPT result in conjunction with reported nasal symptoms (VAS) at the level of $\geq 55 \mathrm{~mm}$ or $\geq 5$ points. In the case of airflow resistance of $\geq 20 \%$ at $150 \mathrm{~Pa}$ with the subjective component (VAS) of $\geq 35 \mathrm{~mm}$ or $\geq 3$ points, the result is considered to be moderately positive [4]. Moreover, another document, which was issued in 2017, defines the RMM result as positive when airflow reduction in a specified unit of time reaches $100 \%$ of that obtained during a "provocation" with a control solution [7].

The RMM measurements conducted as part of NPT three times at 15-minute intervals illustrate changes in nasal patency, separately for the right and left and for both nasal cavities combined. In the case of a strongly positive NPT result, the extent of nasal occlusion prevents evaluation of the airflow resistance value for the pressure of 150 or $100 \mathrm{kPa}$. Additionally, the constant production of serous mucosal secretion prevents tape from being attached to the nostrils, and the use of nasal plugs instead of the tape distorts the rhinomanometry curve by excluding the region of the nasal vestibule.

\section{Peak nasal inspiratory flow testing}

Peak nasal inspiratory flow evaluation is the second most common technique of nasal patency assessment as part of NPT and is an alternative to RMM [26]. The PNIF is a very useful parameter in assessing the effectiveness of immunotherapy in pharmacological studies, as well as in assessing nasal patency in the context of surgical procedures [27]. The PNIF testing is characterized by high sensitivity (higher than RMM) ranging from 66\% to $77 \%$ and specificity of $80 \%$ (compared to RMM specificity of $77 \%$ ) [11].

Not unlike a peak flow meter (for measuring expiratory airflow), a PNIF meter is a very useful tool for monitoring respiratory flow at home [28]. One important advantage of a PNIF meter is its availability and a relatively low cost in comparison with that of other nasal patency assessment techniques. A PNIF meter includes a suitable resuscitation (anesthesia) mask in one of two sizes: 0 (pediatric) and 5 (adult). The mask is latex-free and contains no toxic materials. The range of measurable nasal inspiratory flow is 0-350 l/min. The patient takes a maximum inspiration with the mouth closed. The final result is the mean of three normal, repeated inspiratory flow measurement values.

\section{Peak nasal inspiratory flow in nasal provocation testing}

One considerable drawback of PNIF assessment technique is that, unlike RMM or AR, it offers no param- 
etrization (via computer analyses) of nasal passage measurements. Attempts to standardize PNIF values yielded inconsistent results, due to the fact that a number of factors affect the final result [29].

Physical exercise may considerably affect PNIF test results, hence the necessity of letting the patient acclimatize prior to undergoing a PNIF test, which is also the case prior to a nasal allergen provocation test [1]. Ottaviano et al. demonstrated significantly higher flow rates following an exercise stress test in comparison to those measured before the test (before 186.9 \pm 59.4 ; after $225.4 \pm 76.1 \mathrm{l} / \mathrm{min}$ ) [30]. Nasal patency measured via RMM is significantly reduced in smokers. Interestingly, Polish studies demonstrated a significant decrease in PNIF rates also in passive smokers [31]. Some conditions, especially inflammatory ones - such as allergic rhinitis - are also characterized by nasal occlusion. This manifests as the following PNIF results: $65.94 \pm 18.32 \mathrm{l} / \mathrm{min}$ (range: 30 $120 \mathrm{l} / \mathrm{min}$ ) in patients diagnosed with nasal allergies and $130.73 \pm 26.64 \mathrm{l} / \mathrm{min}$ (range: $90-200 \mathrm{l} / \mathrm{min}$ ) in non-allergic individuals [11].

The PNIF meter is the most commonly used tool for nasal patency assessment and PNIF is measured predominantly in allergen exposure chambers [5]. Allergenspecific NPT with 4,000 grass pollen grains $/ \mathrm{m}^{3}$ exposure reduced the nasal patency (based on PNIF measurements) by $29.7 \%$; 8,000 grass pollen grains $/ \mathrm{m}^{3}$ exposure reduced nasal patency by $36.8 \%$, whereas in the control group the nasal patency was reduced by $8.9 \%$ [27]. The most recent allergen-specific NPT standards stipulate that a decrease in PNIF by $\geq 40 \%$ combined with a subjective discomfort rating of $\geq 55 \mathrm{~mm}$ (or $\geq 5$ points) should be considered a highly positive result. Conversely, a decrease in PNIF by $\geq 20 \%$ combined with a subjective rating of $\geq 35 \mathrm{~mm}$ (or $\geq 3$ points) should be considered a moderately positive result [4].

Unfortunately, the maximum inspiration which must be taken during nasal allergen provocation tests carries a risk of depositing allergens in the lower airways, which is of particular importance in the group of bronchial asthma patients.

\section{Acoustic rhinometry}

The use of AR and the diagnostic significance of this technique in rhinological conditions have been demonstrated in a number of papers. Assessments of the nasal cavity (especially the first $6 \mathrm{~cm}$ ) via AR correlate with computed tomography $(\mathrm{CT})$ and magnetic resonance imaging (MRI) findings [1]. Acoustic rhinometry allows for a non-invasive measurement of the nasal space. Unlike RMM, AR helps assess the structure of the nasal passages via introducing a sound signal into the nostrils. Depending on the type of the device, this signal can be in the form of a single acoustic pulse or can be generated continuously. The sound reflects off the nasal passage walls, nasal septum, and the nasopharynx and returns towards the sound source, where it is recorded with a microphone. The result of the assessment is in the form of a graph illustrating the size (cross-sectional area) of the nasal passages along their course (Figure 1). The AR curve (or rhinogram) is plotted against a horizontal axis (representing the distance from the sound source into the nasal cavity) and a vertical axis (representing the cross-sectional area of nasal passages). Importantly, the results should be interpreted based on the specific segments of the rhinogram rather than any points on the axes. The nasal valve (isthmus nasi) and the anterior end of the inferior concha are of crucial importance in AR result interpretation. Under normal conditions, the smallest cross-sectional area of the nasal cavity is at the nasal valve; its value below $0.28 \mathrm{~cm}^{2}$ in AR indicates septal deviation. Conversely, in the case of a positive NPT result, the smallest cross-sectional area of the nasal cavity is at the anterior end of the inferior concha - which is a target site of allergic reaction.

\section{Acoustic rhinometry in allergen-specific nasal provocation testing}

Due to its high sensitivity, specificity, and reproducibility, AR is of high diagnostic value in the field of rhinology and allergy. The AR is used for assessing nasal physiology (nasal cycle), pre- and postoperative status (e.g. in septoplasty), and medical treatment, as well as for monitoring obstructive sleep apnea, evaluating nasal polyps, and for NPT. One definite advantage of this technique is the possibility of recording edematous changes in the nasal mucosa irrespective of the patient's cooperation (unlike in RMM, where unilateral or bilateral nasal passage occlusion makes it impossible to conduct the assessment); another advantage of AR is that it is an easy assessment (it can be conducted in 3-year-old children) [1]. The AR result interpretation is mostly based on evaluating the minimal cross-sectional area (MCA) [32], other cross-sectional areas along the rhinogram [33], and the nasal cavity volume [34-36]. One very interesting suggestion for AR result interpretation is to assess cross-sectional areas of the nasal cavity at specified points on the rhinogram (CSA-1 and CSA-2), which correspond to the nasal valve and the anterior part of the inferior concha, respectively. Interestingly, Samolinski et al. observed the greatest change in cross-sectional areas occurring $3 \mathrm{~cm}$ beyond the critical site of the allergic reaction (CSA-2) on the rhinogram. In order to assess reactivity, Samoliński et al. additionally used a formula for the nasal mucosa relative reactivity: $\mathrm{Re}=\mathrm{CAll}-\mathrm{CAI} / \mathrm{CAI} \times 100 \%=\Delta$, where Re is reactivity, $\Delta$ is change, CAI is CSA-2 prior to allergen provocation, and CAII = CSA-2 following allergen provocation [1]. However, according to most literature reports the parameter most commonly used as the basis for interpreting AR results is MCA, which varies in dif- 
Rhinogram following application of a control

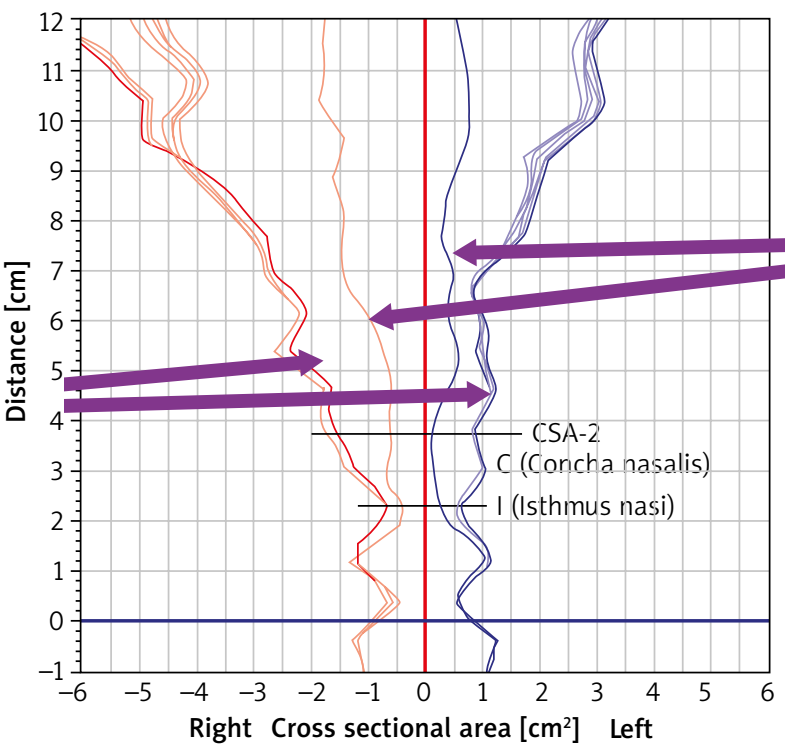

Rhinogram following NPT

Figure 1. Nasal obstruction assessed with acoustic rhinometry

ferent ethnicities. The MCA reported in Caucasians was $0.72 \pm 0.02 \mathrm{~cm}^{2}[37,38]$, in certain Asian populations 0.62 $\pm 0.19 \mathrm{~cm}^{2}$ [38], Negro $0.88 \pm 0.22 \mathrm{~cm}^{2}$ [38], Indian 0.70 $\pm 0.16 \mathrm{~cm}^{2}$ [39], Anglo-Saxon $0.71 \pm 0.15 \mathrm{~cm}^{2}$ [39], and in a Chinese population $0.75 \pm 0.03 \mathrm{~cm}^{2}$ [40]. Moreover, MCA and CSA are known to increase over time as the person develops and grows older. This phenomenon is particularly noticeable at the age between 11 and 14 years [41]. As in the case of nasal patency assessment via RMM and PNIF, physical exercise also significantly affects the volume and cross-sectional areas of the nasal cavity [42].

In light of the most recent standards, a result of NPT via $A R$ is considered to be positive when nasal cavity cross-sectional areas (particularly CSA-2) decrease by $\geq 40 \%$ and at the same time a subjective assessment yields $\geq 55 \mathrm{~mm}$ or $\geq 5$ points. For the sake of comparison, a result of NPT via AR is considered to be moderately positive when nasal patency (measured via AR as the sum of both CSAs at the 2-6 cm segment of the nasal cavity) drops by $\geq 27 \%$ and a subjective assessment yields $\geq 35 \mathrm{~mm}$ or $\geq 3$ points [4]. However, a consensus of experts on nasal and conjunctival allergen provocation testing defined a positive result as a situation when the patient's nasal volume/MCA decreases by $\geq 25 \%$ [7].

Another problem in result standardization, irrespective of the various nasal patency assessment techniques, is the concurrent phenomenon of the nasal cycle, described in detail in papers by Gotlib et al. [32]. Physiological, alternate changes in nasal patency occur in nearly $80 \%$ of evaluated patients [25]. Inability to accurately interpret assessment findings may yield a false positive test result. A 7-hour observational study of spontaneous changes in nasal patency measured by a PNIF meter and
RMM showed variability of the respective evaluated parameters by $15.78 \%$ and $26.38 \%$ [26]. This is why it is so important to bilaterally assess changes in nasal patency (following an earlier allergen application into both nostrils) and, at the same time, use a subjective grading of the patient's discomfort.

\section{Conclusions}

Careful selection of nasal patency assessment techniques for NPT and skillful interpretation of the findings are crucial for a better understanding of the complex phenomena accompanying a local allergic response.

\section{Conflict of interest}

The authors declare no conflict of interest.

\section{References}

1. Samoliński B, Rapiejko P, Krzych-Fałta E et al. Standardy wykonywania donosowych prób prowokacyjnych. Postep Dermatol Alergol 2010; 27: 141-60.

2. Samoliński B, Rapiejko P. Odpowiedź wczesna po donosowej próbie prowokacyjnej z alergenem. Postep Dermatol Alergol 2010; 27: 170-2.

3. Samoliński B, Rapiejko P. Odpowiedź późna po donosowej próbie prowokacyjnej z alergenem. Postep Dermatol Alergol 2010; 27: 173-6.

4. Augé J, Vent J, Agache I, et al. EAACI Position paper on the standardization of nasal allergen challenges. Allergy 2018; 73: 1597-608.

5. Pfaar O, Calderon MA, Andrews CP, et al-Allergen exposure chambers: harmonizing current concepts and projecting the 
needs for the future - an EAACI Position Paper. Allergy 2017; 72: $1035-42$.

6. https://sjp.pwn.pl/sjp/obiektywizacja;2491485.html (available at: 06.12.2018).

7. Pepper AN, Ledford DK. Nasal and ocular challenges I Allergy Clin Immunol 2018; 141: 1570-7.

8. Samoliński B, Krzych-Fałta E. Guidelines/recommendations. Nasal allergen challenge. Alergologia Polska - Polish Journal of Allergology 2018; 5: 192-6.

9. Krzych-Fałta E, Furmańczyk K, Samoliński B. Specificity and sensitivity assessment of selected nasal provocation testing techniques. Adv Dermatol Allergol 2016; 33: 464-8.

10. Krzych-Fałta E, Samoliński B. Optical rhinometry - new challenges and possibilities of rhinitis diagnostics and not only. Otolaryngol Pol 2016; 70: 31-4.

11. Martins de Oliveira GM, Rizzo JÂA, Camargos PA, et al. Are measurements of peak nasal flow useful for evaluating nasal obstruction in patients with allergic rhinitis? Rhinology 2015; 53: 160-6.

12. van Spronsen E, Ingels KJ, Jansen AH, et al. Evidence-based recommendations regarding the differential diagnosis and assessment of nasal congestion: using the new GRADE system. Allergy 2008; 63: 820-33.

13. Emeryk A, Tuszkiewicz-Misztal E, Bartkowiak-Emeryk M. Obiektywne badania drożności nosa w praktyce alergologicznej u dzieci. Alergia 2003; 29-33.

14. Clement PA. Different types of rhinomanometres, standarization, pathologic shapes of rhinomanometric recordings, pifalls, and possible errors. Facial Plast Surg 1990; 7: 230.

15. Clement PA, Hirsch C. Rhinomanometry - a review. J Otorhinolarygol Relat Spec 1984; 46: 173-91.

16. Krzeski A, Samoliński B. Standaryzacja badań rynomano metrycznych - zalecenia Międzynarodowego Komitetu Standaryzacji Rynomanometrii. Otolaryngol Pol 1994; 48 Supl. 17: 108-11.

17. Clement PAR, Gordts F. Consensus report on acoustic rhinometry and rhinomanometry (Standardisation Committee on Objective Assessment of the Nasal Airway, IRS and ERS Rhinology 2005; 43: 169-79.

18. Krzych-Fatta E, Samoliński B. Rynomanometria. In: Otolaryngologiia Kliniczna. Vol. I. Niemczyk K, Jurkiewicz D, Składzień J, et al. (eds). Medipage, Warszawa 2015; 116-21.

19. Williams HL. The history of rhinometry in North America. Rhinology 1968; 25: 71-100.

20. Malm L, Gerth van Wijk R, Bachert C. Guidelines for nasal provocations with aspects on nasal patency, airflow, and airflow resistance. International Committee on Objective Assessment of the Nasal Airways, International Rhinologic Society. Rhinology 2000; 38: 1-6.

21. Cole P. Stability of nasal airflow resistance. Clin Otolaryngol Allied Sci 1989; 14: 177-82.

22. Jones AS, Lancer JM, Stevens JC, et al. Nasal resistance to airflow (its measurement, reproducibility and normal parameters). J Laryngol Otol 1987; 101: 800-8.

23. Shelton DM, Eiser NM. Evaluation of active anterior and posterior rhinomanometry in normal subjects. Clin Otolaryngol Allied Sci 1992; 17: 178-82.

24. Ohki M, Naito K, Cole P. Dimensions and resistances of the human nose: racial differences. Laryngoscope 1991; 101: 276-8.

25. Suzina AH, Hamzah M, Samsudin AR. Active anterior rhinomanometry analysis in normal adult Malays. J Laryngol Oto 2003; 117: 605-8.
26.Pendolino AL, Nardello E, Lund VJ, et al. Comparison between unilateral PNIF and rhinomanometry in the evaluation of nasal cycle. Rhinology 2018; 56: 122-6.

27. Boelke G, Berger U, Bergmann KC, et al. Peak nasal inspiratory flow as outcome for provocation studies in allergen exposure chambers: a GA²LEN study. Clin Transl Allergy 2017; 7: 33.

28. da Cunha Ibiapina C, Ribeiro de Andrade C, Moreira Camargos PA, et al. Reference values for peak nasal inspiratory flow in children and adolescents in Brazil. Rhinology 2011; 49: 304-8.

29. Krzych-Fałta E, Furmańczyk K, Samoliński B, et al. Nasal patency in Poles in the light of research as part of the project on Epidemiology of Allergic Diseases in Poland. Ann Agric Environ Med 2016; 23: 487-90.

30. Ottaviano G, Ermolao A, Nardello E, et al. Breathing parameters associated to two different external nasal dilator strips in endurance athletes. Auris Nasus Larynx 2017; 44: 713-8.

31. Krzych-Fałta E, Furmańczyk K, Piekarska B, et al. Influence of selected factors on peak nasal inspiratory flow readings - epidemiology of allergic diseases in Poland study. Otolaryngol Pol 2017; 71: 40-4.

32. Gotlib T, Samoliński B, Grzanka A, et al. Dynamics of early phase congestion after nasal allergen provocation. Rhinology 2008; 46: 52-5.

33. Ganslmayer M, Spertini F, Rahm F, et al. Evaluation of acoustic rhinometry in a nasal provocation test with allergen. Allergy 1999; 54: 974-9.

34. Rasp G. Acoustic rhinometry in early and late antigen induced allergic rhinitis. Laryngorhinootologie 1993; 72: 125-30.

35. Modrzyński M, Zawisza E. Specific nasal provocation tests in patients hypersensititive to mould allergens. Med Sci Moni 2005; 11: 44-8.

36. Miyahara Y, Ukai K, Yamagiwa M, et al. Nasal passage patency in patients with allergic rhinitis measured by acoustic rhinometry: nasal responses after allergen and histamine provocation. Auris Nasus Larynx 1998; 25: 261-7.

37. Garcia GJM, Hariri BM, Patel RG, et al. The relationship between nasal resistance to airflow and the airspace minimal cross-sectional area. J Biomech 2016; 49: 1670-8.

38. Morgan NJ, MacGregor FB, Birchall MA, et al. Racial differences in nasal fossa dimensions determined by acoustic rhinometry. Rhinology 1995; 33: 224-8.

39. Gurr P, Diver J, Morgan N, et al. Acoustic rhinometry of the Indian and Anglo-Saxon nose. Rhinology 1996; 34: 156-9.

40. Huang ZL, Wang DY, Zhang PC, et al. Evaluation of nasal cavity by acoustic rhinometry in Chinese, Malay and Indian ethnic groups. Acta Otolaryngol 2001; 121: 844-8.

41. Millqvist E, Bende M. Two-year follow-up with acoustic rhinometry in children. Am J Rhinol 2006; 20: 203-4.

42. Fonseca MT, Machado JA, Pereira SA, et al. Effects of physical exercise in nasal volume. Braz I Otorhinolaryngol 2006; 72: 256-60. 